\title{
Who is Using Telehealth in Primary Care? Safety Net Clinics and Health Maintenance Organizations (HMOs)
}

\author{
Megan Coffman, MS, Miranda Moore, PhD, Anuradha Jetty, MPH, \\ Katbleen Klink, MD, and Andrew Bazemore, MD
}

Despite rapid advancements in telehealth services, only $15 \%$ of family physicians in a 2014 survey reported using telehealth; use varied widely according to the physician's practice setting or designation. Users were significantly more likely than nonusers to work in federally designated "safety net" clinics and health maintenance organizations (HMOs) but not more likely than nonusers to report working in a patient-centered medical home (PCMH) or accountable care organization. (J Am Board Fam Med 2016; 29:432-433.)

Keywords: Accountable Care Organizations, Health Maintenance Organizations, Patient-Centered Care, Family Physicians, Safety-net Providers, Surveys and Questionnaires, Telemedicine, Work

Technological advances provide an avenue to improve patient access to care, ${ }^{1}$ increase the continuity of care, ${ }^{2}$ and improve health outcomes ${ }^{3}$ through telehealth services. A 2014 survey conducted by the American Academy of Family Physicians and analyzed by the Robert Graham Center found that only $15 \%$ of the responding family physicians (557 survey responses; $31 \%$ of the sample) had used telehealth services in the preceding year. ${ }^{4}$ Telehealth services were defined in the survey to mean either direct provision of primary care services, primary care and subspecialist referral services, e-visits, and store and

This article was externally peer reviewed.

Submitted 7 December 2015; revised 31 March 2016; accepted 18 April 2016.

From the American Academy of Family Physicians, Leawood, KS (MC, MM, AJ); the Robert Graham Center, Washington, DC (MC, MM, AJ, AB); and Veterans Affairs (KK).

Funding: This study was funded by Anthem.

Conflict of interest: none declared.

Corresponding author: Megan Coffman, MS, AAFP/Robert Graham Center, 1133 Connecticut Ave NW, Washington, DC 20036 (E-mail: mcoffman@aafp.org).

See Related Commentary on Page 430. forward services. Little is known about how telehealth usage varies by practice setting.

The 2014 American Academy of Family Physicians Telehealth Survey also asked respondents to indicate (through checkboxes) their primary practice location's affiliations or designations for federal designation (federally qualified health center or community health center, rural health clinic, or Indian health service); academic health center; $\mathrm{HMO}$; accountable care organization; and/or certified PCMH. Respondents were able to select all affiliations or designations that applied to their primary practice setting. Telehealth users were statistically more likely than non-telehealth users to be affiliated with a federally designated safety net clinic $(28 \%$ vs $15 \% ; P<.000)$ or an HMO $(19 \%$ vs $11 \% ; P=.01)$ (Table 1).

While previous reports highlighted the limited adoption of telehealth in primary care, these findings suggest greater use among family physicians in safety net and managed care settings. The source of this variation requires further investigation if policymakers wish to understand how family physicians in all settings can use technological advancements to better care for their patients. The lack of significant differences between users and nonusers in a PCMH may suggest a need for greater evidence of telehealth's 
Table 1. Distribution of Family Physicians' Primary Practice Location Affiliations or Designations by Telehealth Usage

\begin{tabular}{lcccc}
\hline $\begin{array}{l}\text { Affiliations or Designations of Primary } \\
\text { Practice Location }\end{array}$ & All Physicians & Telehealth Users* & Non-Telehealth Users & $P$ Value \\
\hline Any affiliation/designation & $994(65.4)$ & $157(73.8)$ & $837(64.3)$ & .045 \\
Federal designation & $291(16.6)$ & $68(28.1)$ & $223(15.0)$ & .0000 \\
Academic health center & $157(11.1)$ & $21(10.7)$ & $136(11.2)$ & .856 \\
Health maintenance organization & $155(12.2)$ & $31(18.7)$ & $124(11.3)$ & .011 \\
Accountable care organization & $395(27.2)$ & $44(22.1)$ & $351(27.9)$ & .113 \\
Patient-centered medical home $(\mathrm{n}=1557)$ & $443(29.6)$ & $63(30.9)$ & $380(29.5)$ & .709 \\
\hline
\end{tabular}

Data are $\mathrm{n}(\%)$ unless otherwise indicated. Selections are not mutually exclusive; thus the columns do not add up to $100 \%$.

*There were 225 telehealth users.

${ }^{\dagger} \chi^{2}$ Test of significance between telehealth users and nonusers.

Source: Robert Graham Center analysis of the 2014 American Academy of Family Physicians Telehealth Survey of Family Physicians.

benefits and incentives for its adoption on the road to practice transformation.

\section{References}

1. Marcin JP, Rimsza ME, Moskowitz WB; Committee on Pediatric Workforce. The use of telemedicine to address access and physician workforce shortages. Pediatrics 2015;136:202-9.

2. Cherry JC. Using telehealth to improve continuity of care. Patient Safety and Quality Healthcare; September 29, 2010. Available from: http://psqh.com/ using-telehealth-to-improve-continuity-of-care. Accessed October 2, 2015.
3. Nundy S, Dick JJ, Chou CH, Nocon RS, Chin MH, Peek ME. Mobile phone diabetes project led to improved glycemic control and net savings for Chicago plan participants. Health Aff (Millwood) 2014;33: $265-72$.

4. Klink K, Coffman M, Moore M, Jetty A, Petterson S, Bazemore A. Family physicians and telehealth: findings from a national survey. Project report. Washington, DC: Robert Graham Center; 2015. Available from: http://www.graham-center.org/ content/dam/rgc/documents/publications-reports/ reports/RGC\%202015\%20Telehealth\%20Report. pdf. Accessed November 24, 2015. 